\title{
A Comparison of 2 Respiratory Devices for Sputum Clearance in Adults With Non-Cystic Fibrosis Bronchiectasis
}

\author{
Yasmin R Silva MHSc PT, Tracy A Greer MHSM, Lucy C Morgan PhD FRACP, Frank Li PhD, \\ and Claude S Farah MBBS PhD FRACP
}

\begin{abstract}
BACKGROUND: Airway clearance techniques are a vital part of routine care for patients with bronchiectasis. There is no clear superior modality. The Flutter combines oscillations $(6-20 \mathrm{~Hz})$ and positive expiratory pressure; the Lung Flute combines positive expiratory pressure and low frequency acoustic waves $(18-22 \mathrm{~Hz})$, to augment clearance. This project aimed to compare these devices. METHODS: This was a randomized crossover study of adult subjects with stable noncystic fibrosis bronchiectasis (expectorating $>25 \mathrm{~mL} / \mathrm{d}$ ). Subjects attended 2 separate out-patient visits, 1 week apart, and completed a supervised sputum clearance regime and Lickert scale (8 questions regarding subjects' perception of the experience using each device). Total sputum expectorated during supervised intervention (T1) and after $30 \mathrm{~min}$ from the end of T1 (T2) was recorded as wet sputum weight. Total wet sputum weight desiccated in a microwave (10 min at 300 watts), allowed measurement of total dry sputum weight. Data were compared using paired $t$ test. RESULTS: We recruited 40 subjects with a mean \pm SD age of $63 \pm 16$ y. Overall, there was no significant difference in wet sputum weight (Flutter, $5.78 \pm 6.47 \mathrm{~g}$; Lung Flute, $5.75 \pm 0.22 \mathrm{~g}$ ) and dry sputum weight (Flutter, $0.40 \pm 0.86 \mathrm{~g}$; Lung Flute, $0.22 \pm 0.21 \mathrm{~g}$ ). At T1, wet sputum weight was higher for the Flutter $(5.10 \pm 6.26 \mathrm{~g})$ compared with the Lung Flute $(3.74 \pm 3.44 \mathrm{~g})(P=.038)$. At $\mathrm{T} 2$, wet sputum weight was higher for the Lung Flute $(2.02 \pm 3.01 \mathrm{~g})$ compared with the Flutter $(0.68 \pm 0.75 \mathrm{~g})$ $(P=.001)$. Subjects perceived the Flutter as being significantly better at clearing secretions $(P=$ $.01)$, easy to understand $(P=.03)$, and simple to use $(P=.01)$ compared with the Lung Flute. CONCLUSIONS: Both devices were well-tolerated and successfully augmented secretion clearance. Most subjects preferred the Flutter because of increased speed of secretion clearance, and greater ease of use. Key words: respiratory devices; sputum expectoration; bronchiectasis. [Respir Care 2017;62(10):1291-1297. (c) 2017 Daedalus Enterprises]
\end{abstract}

\section{Introduction}

Bronchiectasis is a lung disease characterized by repeated cycles of airway infection and inflammation that

\footnotetext{
Ms Silva and Dr Li are affiliated with the Physiotherapy Department, and Ms Greer, Dr Morgan, and Dr Farah are affiliated with the Respiratory Department, Concord Repatriation General Hospital, Concord, New South Wales, Australia.

The authors have disclosed no conflicts of interest.

Correspondence: Yasmin Silva MHSc PT, Physiotherapy Department, Concord Repatriation General Hospital, Concord, New South Wales 2139, Australia. E-mail: yasmin.silva@sswahs.nsw.gov.au.
}

DOI: $10.4187 /$ respcare.04929 ultimately result in airway and lung parenchyma destruction. Bronchiectasis is associated with damaged ciliated epithelium and compromised mucociliary clearance. ${ }^{1}$ In the affected areas, there is excess production of mucus due to glandular hyperplasia. The mucus becomes colonized by bacteria and then hyperviscous and purulent. Impaired clearance of this mucus predisposes to mucus retention and recurrent respiratory infections. ${ }^{1}$

Airway clearance techniques are integral to the management of bronchiectasis, clearing conducting airways, improving pulmonary ventilation, and reducing cough and breathlessness. ${ }^{2}$ Respiratory therapists and physiotherapists use a spectrum of airway clearance maneuvers such as active-cycle-of-breathing technique with or without gravity-assisted drainage and manual techniques as well as positive pressure devices with or without oscillations. ${ }^{2}$ 
These techniques are used in combination with forced expiration technique to move the mobilized secretions to proximal airways to be cleared, which then may require subsequent cough. ${ }^{3}$ Active-cycle-of-breathing technique, gravity-assisted drainage, and manual techniques are often difficult for elderly patients and those with severe disease due to comorbidities and reduced respiratory muscle and cough strength. ${ }^{4,5}$ Any effective secretion clearance regime needs to be able to be performed independently, be integrated into normal daily activities, and be cost-effective.

Several airway clearance devices are commercially available to aid in sputum expectoration and optimizing outcomes, but to date, no single device has demonstrated clear superiority. ${ }^{6}$ The Flutter (Aptalis Pharma, Bridgewater, New Jersey) and the Lung Flute (Medical Acoustics, Buffalo, New York) are 2 commercially available intrathoracic oscillatory positive expiratory pressure (PEP) devices designed to augment sputum expectoration. The pressure generated by PEP during expiration stabilizes airways, assists mucus movement, and prevents airway closure, thereby improving ventilation. ${ }^{4,7}$ In addition, studies using the Flutter found that oscillatory waves with varying frequencies are transmitted through the airways, resulting in shearing forces that reduce viscoelasticity of bronchial secretions $^{8}$ and easier transportation. ${ }^{9}$ The frequencies for the Lung Flute are also similar to those for the Flutter; however, these 2 devices have never been compared.

The Flutter (\$68) is a pipe-like device with a hardened plastic mouthpiece at one end, a protective perforated cover at the other end, and a high-density stainless steel ball resting in a plastic circular cone on the inside (Fig. 1). As the subject exhales through the Flutter, the steel ball is intermittently displaced, causing oscillations of air flow and PEP, which are transmitted down the tracheobronchial tree. ${ }^{4}$ PEP develops in the range of $10-25 \mathrm{~cm} \mathrm{H}_{2} \mathrm{O}$ at an oscillatory frequency of approximately $15 \mathrm{~Hz}$. Tilting the device adjusts the frequency to achieve the greatest amount of airway vibration (the individual's pulmonary resonance frequency). ${ }^{4}$ The Flutter has been shown to increase sputum expectoration and to diminish peripheral airway resistance in addition to cough in subjects with bronchiectasis. ${ }^{10}$ However, when compared with combinations of gravity-assisted drainage and activecycle-of-breathing technique, it has demonstrated no advantage in terms of sputum expectoration, oxygen saturation, spirometry measures, health-related quality of life, or breathlessness in patients with bronchiectasis. ${ }^{11-13}$ One study showed, a greater subject preference for the Flutter compared with active-cycle-of-breathing technique with or without gravity-assisted drainage. Patients with low expiratory flows may find it difficult to generate oscillatory PEP with the Flutter. ${ }^{14}$ In addition, some patients do not like the feeling experienced when expiring through the Flutter and find the oscillating wave uncomfortable.

\section{QUICK LOOK}

\section{Current knowledge}

A number of devices have been developed that use oscillatory positive expiratory pressure to enhance mucus clearance in bronchiectasis. Patient comfort is important in promoting compliance with secretion clearance regimens. Low expiratory flows reduce the effectiveness of these devices.

\section{What this paper contributes to our knowledge}

Both devices were well-tolerated and augmented secretion clearance. However, subjects perceived the Flutter as more useful because it was easier to use and faster at clearing secretions.

The Lung Flute ( $\$ 56$, including 14 reeds) is a relatively new device that uses sound waves to vibrate airway secretions. The Lung Flute has a mouthpiece and replaceable reed inside a $36.8-\mathrm{cm}$-long plastic tube (Fig. 2). Unlike the Flutter that uses oscillatory back pressure, the Lung Flute has a unique mechanism based on acoustic energy that may benefit subjects with low expiratory flows who may find the Flutter difficult to use. Exhaling into the Lung Flute needs to be vigorous enough to make the reed oscillate. The oscillation of the reed generates sound waves of $16-22 \mathrm{~Hz}$ with an output of $110-115 \mathrm{~dB}$ using $2.5 \mathrm{~cm} \mathrm{H}_{2} \mathrm{O}$ of PEP. ${ }^{15}$ The sound waves are propagated down the tracheobronchial tree and vibrate the secretions. This enhances mucociliary clearance. ${ }^{15}$ The Lung Flute has been shown to be as effective as active-cycle-ofbreathing technique on sputum expectoration in a single short (3 day) study in subjects admitted to the hospital with an infective exacerbation of bronchiectasis, but no longerterm or comparative studies have been published to date. ${ }^{16}$ This study aimed to compare the efficacy of sputum expectoration and subject acceptability of the Flutter and the Lung Flute in adults with stable, productive bronchiectasis.

\section{Methods}

\section{Study Population}

Consecutive patients over the age of 18 y with stable non-cystic fibrosis bronchiectasis (diagnosed on high-resolution computed tomography) and productive of $>25 \mathrm{~mL}$ of sputum/d attending the Bronchiectasis Clinic at Concord Repatriation General Hospital (Sydney, Australia) were invited to participate in the study between March 2013 and July 2014. The study was approved by the Concord Repatriation General Hospital Human Research and 


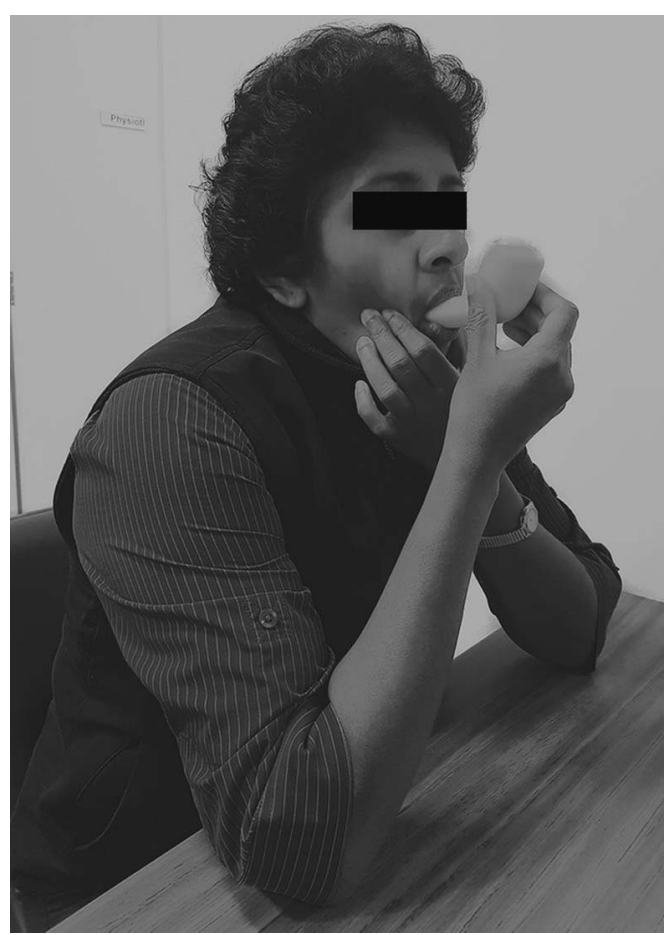

Fig. 1. Flutter.

Ethics Committee (LNR/12/CRGH/188), and informed consent was obtained from all subjects. The research protocol has been listed in the Australia New Zealand Trials Registry, available at www.ANZCTR.org.au, under the identification number ACTRN12614001072606.

Patients were excluded if they were unable to perform airway clearance with the respiratory devices, were unable to complete a questionnaire in English, had intercurrent pneumothorax or hemoptysis, or experienced an exacerbation of bronchiectasis (in the 4 weeks before or during the study) that required a change in treatment.

\section{Study Design}

After attending the bronchiectasis clinic appointment, baseline spirometry was done. This was a randomized crossover study, where each subject received both treatments (Flutter and Lung Flute) and each acted as their own control. The order of treatment was chosen by computer-generated randomization with concealed allocation. The trial involved 2 sessions with the allocated sputum clearance device, 1 week apart (Fig. 3). The 2 sessions were delivered at the same time of the day. Maintenance medications were continued throughout the trial. Subjects were advised to withhold usual airway clearance for $24 \mathrm{~h}$ before attendance.

Each visit consisted of a supervised treatment session (T1) using either the Flutter or the Lung Flute and a 30-min rest period (T2). To minimize variability within and between sub-

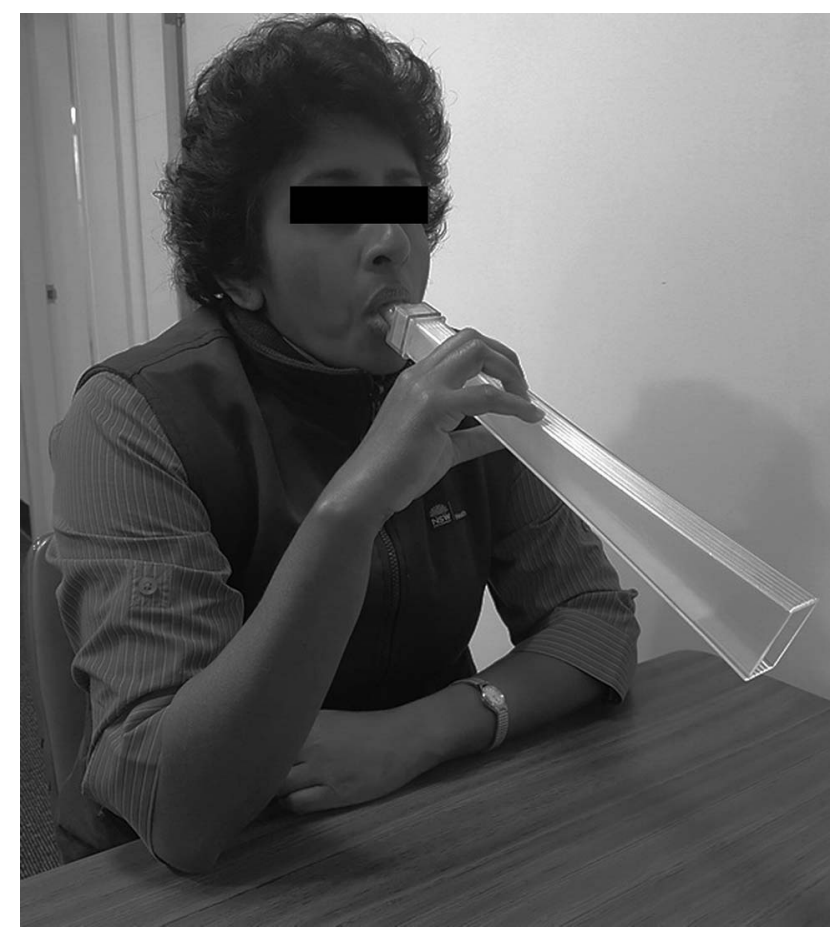

Fig. 2. Lung Flute.

jects, all treatments were supervised and administered by the same senior respiratory physiotherapist. Subjects were instructed to clear secretions without swallowing, and all sputum expectorated was collected during both T1 and T2. During the treatment sessions, the subjects were seated on a chair, maintaining good posture, the neck and shoulders relaxed with the elbows resting on a table (see Figs. 1 and 2).

Physiotherapy with the Flutter was performed according to manufacturer's instructions (http://www.allergan.com/ assets/pdf/flutter_pi, Accessed June 2, 2017). The Flutter treatment session required each subject to inhale more deeply than usual and hold this breath for $2-3 \mathrm{~s}$. Then the subject was instructed to place the mouthpiece of the Flutter into the mouth and exhale, keeping the cheeks stiff and suppressing the urge to cough. All subjects were asked to stabilize the cheeks with the free hand to prevent oscillations of the cheek, for consistency of the technique (Fig. 1). During expiration, the subject was instructed to tilt the Flutter upwards and downwards by a few degrees to induce maximum oscillations within the chest wall. This cycle was repeated 5-10 times, suppressing the urge to cough. The subjects were then instructed to inhale deeply and to exhale forcefully through the Flutter 1-2 times, followed by a forced expiration technique to eliminate secretions. The cycle of Flutter and forced expiration technique was repeated until the subject had a dry-sounding huff. This was the defined end point (T1). If this defined end point was not achieved within $30 \mathrm{~min}$, the session was judged complete. 

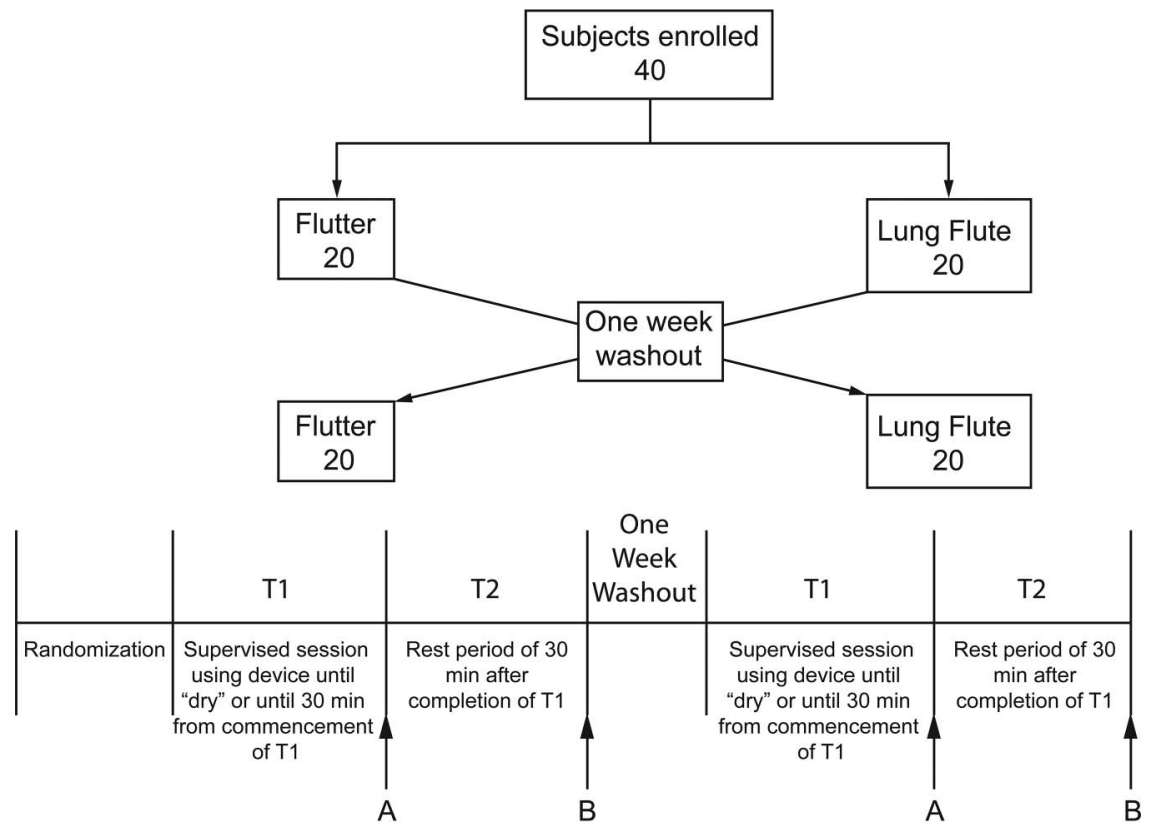

Fig. 3. Flow chart. At each supervised visit, subjects used the device until dry or until 30 min had passed. Expectorated sputum was then collected (A). After a 30-min rest period, expectorated sputum was collected again (B).

Physiotherapy with the Lung Flute was performed according to manufacturer's instructions (http://www. lungflute.com/Therapeutic.aspx, Accessed June 2, 2017). The Lung Flute treatment session required each subject to inhale more deeply than usual. Then the subject was instructed to place the mouthpiece of the Lung Flute into the mouth in a downward position (Fig. 2). The subject would then exhale into the device, with enough vigor (as if trying to blow out a candle) to make the reed oscillate, causing a fluttering noise. After exhaling into the Lung Flute twice, subjects would remove the mouthpiece and take 5 normal breaths. This was repeated 10 times, followed by 2 or 3 mid-to-low-volume huffs and coughs to complete 1 cycle. The whole cycle was repeated one more time. After the normal breaths at the end of the second cycle, the subject performed mid-to-low-volume huffs until the subject had a drysounding huff. This was the defined end point (T1).

Following the end of the treatment session (T1), subjects were instructed to sit on a chair and rest for $30 \mathrm{~min}$ (T2). If the subjects felt the need to cough or clear secretions spontaneously during $\mathrm{T} 2$, all sputum expectorated was collected.

\section{Outcomes and Measurements}

Expectorated wet sputum weight is an accepted, simple, noninvasive short-term clinical outcome measure of airway clearance. ${ }^{17}$ Dry sputum weight is considered a more accurate assessment of sputum weight than wet sputum weight because saliva, in varying quantities, can dilute the expectorated sputum. ${ }^{18,19}$ To evaluate the effectiveness of airway clearance, the primary outcome measures will be the expectorated weight of wet and dry sputum. The secondary outcome measure was subject acceptability and tolerability of the devices. Both outcome measures were evaluated by an assessor who was blinded to the device used.

Wet sputum weight was measured using an A\&D HL-i Digital Compact Scale (accurate to $200 \times 0.1 \mathrm{~g}$ ). A preweighed cup was given to each subject, and the cup and sputum contents were re-weighed to calculate the sputum weight. The wet sputum collected throughout T1 (A) and T2 (B) were noted as T1 wet sputum weight and T2 wet sputum weight (Fig. 3). The total wet sputum weight was obtained by adding together $\mathrm{T} 1$ and $\mathrm{T} 2$ wet sputum weight.

There are no clear guidelines to obtain absolute dry sputum weight. Microwave drying has been shown to have the advantage of significantly shortening the drying process by automatically adjusting the energy absorption levels of the wet products. ${ }^{20}$ Two previous studies had used 500 watts for $30 \mathrm{~min}$ to obtain dry sputum weight from wet sputum weight samples $>10$ g. ${ }^{18,19}$ It was not clear whether this same methodology could be used to desiccate smaller sputum samples for this study. A pilot trial was therefore conducted, and it was noted that quantities of sputum $<10 \mathrm{~g}$ scorched during the final stages of the drying process. Wattage and drying time were consequently reduced, and the total wet sputum weight was desiccated in a microwave at 300 watts for $10 \mathrm{~min}$ to determine the total dry sputum weight. Samples $>10 \mathrm{~g}$ were divided into smaller portions, and the process was repeated as described. 


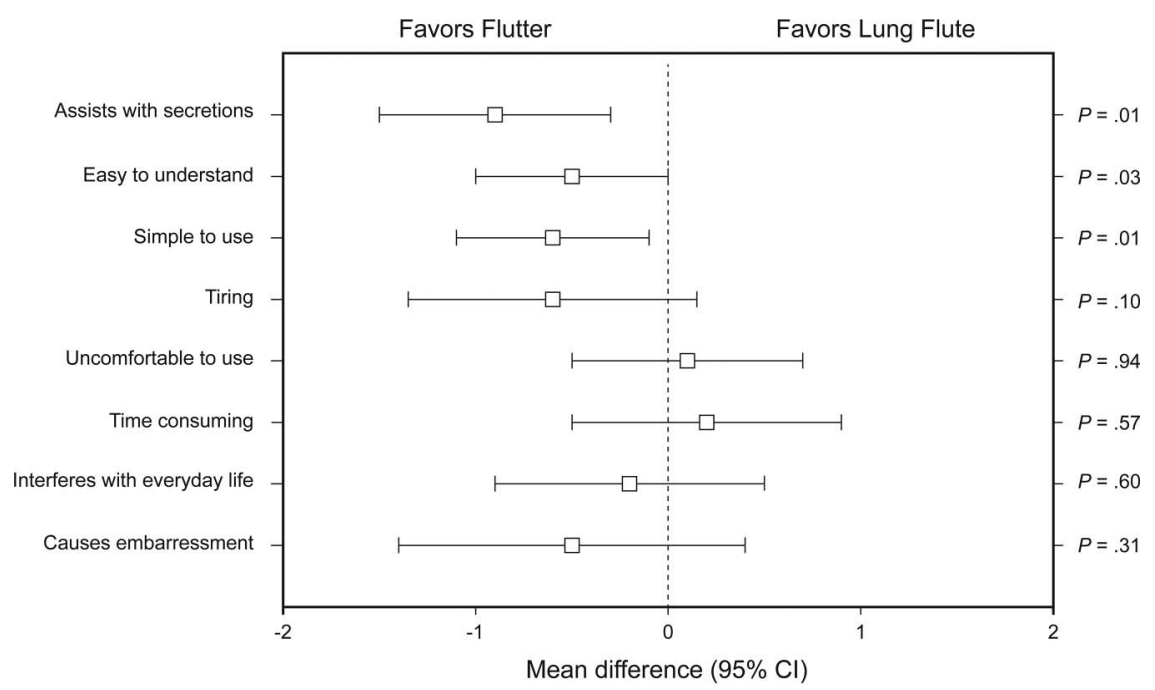

Fig. 4. Likert scale response to the 2 devices.

Subject acceptability and tolerability was assessed at end of $\mathrm{T} 2$ by asking the subjects to complete a Likert scale used by Eaton. ${ }^{12}$ A Likert scale included usefulness, ease of understanding of instructions, ease of performance, degree of tiredness, discomfort, time consumption, interference with everyday life, and embarrassment $(1=$ extremely satisfied, $7=$ not at all satisfied). At the completion of the final visit, the subjects were asked to state their preferred clearance technique.

\section{Statistical Analysis}

A sample size of 34 subjects in each group was needed to detect an effect size within subjects of $0.5 \mathrm{SD}$ between treatments, allowing for a type-1 error of 5\% and a statistical power of $80 \% .{ }^{20}$ Data were analyzed using SPSS 21 (IBM, Armonk, New York). Differences in Likert scales between treatments were computed and, because these were approximately normally distributed, are summarized as mean differences with $95 \% \mathrm{CI}$ in Figure 4. $P$ values were computed using paired $t$ tests and, where there were extreme values, a Wilcoxon signed-rank test. Statistical significance was set at $P<.05$.

\section{Results}

Forty subjects were recruited, and all completed the study. Subject characteristics are listed in Table 1. All subjects, when using either device, reached the end point of T1 within 20-25 min.

The mean weight of sputum expectorated while using the devices (T1 wet sputum weight) was significantly greater with the Flutter compared with the Lung Flute. However, the mean sputum expectorated 30 min after completion of using the devices (T2 wet sputum weight) was
Table 1. Subject Characteristics

\begin{tabular}{lc}
\hline \hline \multicolumn{1}{c}{ Characteristics } & Values \\
\hline Male/female sex, $n$ & $11 / 29$ \\
Age, mean $\pm \mathrm{SD} \mathrm{y}^{\prime}$ & $63 \pm 16$ \\
$\mathrm{FEV}_{1}$, mean $\pm \mathrm{SD} \mathrm{L}$ & $1.52 \pm 0.75$ \\
$\mathrm{FEV}_{1}$, mean $\pm \mathrm{SD} \%$ predicted & $66.5 \pm 30.1$ \\
$\mathrm{FVC}_{\text {, mean } \pm \mathrm{SD} \mathrm{L}}$ & $2.31 \pm 0.79$ \\
$\mathrm{FVC}_{\text {, mean }} \pm \mathrm{SD} \%$ predicted & $80.9 \pm 23.7$ \\
$\mathrm{FEV}_{1} / \mathrm{FVC}$, mean $\pm \mathrm{SD}$ & $0.66 \pm 0.19$ \\
\hline$N=40$. & \\
\hline
\end{tabular}

significantly greater with the Lung Flute compared with the Flutter. Overall, there was no significant difference in the total wet sputum weight and dry sputum weight for sputum cleared using either device (Table 2).

The subjects perceived Flutter to be significantly more useful for clearing secretions, easy to understand, and simple to use (Fig. 4). The Flutter tended to be less tiring and embarrassing to use compared with the Lung Flute; however, this was not significant. Both devices were perceived as timeconsuming, uncomfortable to use, and interfering with everyday life (Fig. 4). At the completion of the study, in response to a specific enquiry regarding preference, 25 preferred the Flutter, 4 preferred the Lung Flute, and 11 were non-committal.

\section{Discussion}

This is the first study to compare the efficacy of the Flutter and the Lung Flute in subjects with stable noncystic fibrosis bronchiectasis expectorating $>25 \mathrm{~mL}$ of sputum/d. The amount of sputum expectorated is an outcome measure of key importance to subjects. Both devices 
Table 2. Comparison of Total Sputum Expectorated With Each Device

\begin{tabular}{lcccr}
\hline \hline \multirow{2}{*}{ Parameter } & \multicolumn{2}{c}{$\begin{array}{c}\text { Sputum Weight, } \\
\text { Mean } \pm \text { SD g }\end{array}$} & $\begin{array}{c}\text { Mean Difference } \\
(95 \% \text { CI })\end{array}$ & $P$ \\
\cline { 2 - 3 } & Flutter & Lung Flute & & \\
\hline T1 WSW & $5.10 \pm 6.26$ & $3.74 \pm 3.44$ & $-1.36(-3.0$ to 0.2$)$ & .038 \\
T2 WSW & $0.68 \pm 0.75$ & $2.02 \pm 3.01$ & $1.34(0.5-2.2)$ & $<.001$ \\
Total WSW & $5.78 \pm 6.47$ & $5.75 \pm 0.22$ & $-0.03(-1.8$ to 1.8$)$ & .91 \\
Total DSW & $0.40 \pm 0.86$ & $0.22 \pm 0.21$ & $0.18(-0.5$ to 0.1$)$ & .76 \\
& & & & \\
T1 = during supervised intervention & & & \\
WSW = wet sputum weight & & & \\
T2 = 30 min from the end of T1 & & & \\
DSW = dry sputum weight & & & \\
\hline
\end{tabular}

helped this small cohort of stable subjects to clear airway secretions. There were no significant differences in the total amount of sputum cleared by individual subjects (wet sputum weight and dry sputum weight) using either device, implying that both help to clear excess secretions. However, subjects were able to expectorate sputum to end point (no further spontaneous expectoration and a drysounding huff) more quickly with the Flutter.

There are several plausible explanations for this more time-efficient clearance. The Flutter produces a 10-fold higher PEP than the Lung Flute $\left(10-25 \mathrm{~cm} \mathrm{H}_{2} \mathrm{O}\right.$ compared with $2.5 \mathrm{~cm} \mathrm{H}_{2} \mathrm{O}$ ). The higher PEP stabilizes the airway during expiration and prevents collapse of the floppy bronchiectatic airway, accelerating expiratory air flow and moving mucus upward to the trachea. The Flutter generates a high peak expiratory-inspiratory flow ratio $>1.1 .^{21}$ This is considered the critical ratio required for annular flow of secretions toward the oropharynx. ${ }^{21}$ The Flutter is designed specifically to produce a mean oscillation frequency of 11.3 Hz, which is close to the optimal frequency range to facilitate mucociliary clearance in human airways. ${ }^{22}$ This oscillation frequency has the added potential to alter the physical properties of mucus, which in combination with the splinting of the airways by PEP and the high expiratory-inspiratory flow may assist sputum expectoration. ${ }^{9}$

The Lung Flute also augments sputum clearance. In this study, use of the Lung Flute facilitated sputum expectoration throughout the time period, and this clearance continued into the last 30-min period (T2). This was longer than the time to dry for the use of the Flutter and similar to the delayed clearance reported by Fujita et $\mathrm{al}^{23}$ when the Lung Flute was used for sputum induction for subjects with suspected tuberculosis. There are several plausible explanations for the prolonged time to dry with Lung Flute. The Lung Flute generates lower PEP $\left(2.5 \mathrm{~cm} \mathrm{H}_{2} \mathrm{O}\right)$ than the Flutter; therefore, the air pressure applied per unit area of lung is lower, and there is the potential for dynamic airway collapse during expiration and secretions intermittently trapped distal to this collapse. The prolonged time to dry was identified by our subjects as a disadvantage of the Lung Flute. Additionally, the Lung Flute was perceived to be more expensive than the Flutter because a reed requires replacement every 2 weeks, with each additional replacement reed kit (14 reeds) retailing for $\$ 16$.

Assessment of device efficacy was based on the amount of sputum produced within the treatment time period because it is directly visible for the subjects. This is important because one of the potential effects of airway clearance is to make the sputum clearance more efficient for the subject. Both devices were well-accepted and well-tolerated. Subjects perceived the Flutter to be significantly more useful for clearing secretions, probably because the secretions were cleared quickly, and therefore the clearance regime took less time (in a highly burdensome and time-consuming daily routine) and provided longer cough-free intervals. The verbal instructions for Flutter were perceived by subjects as easier to understand, and this device was perceived as simpler to use.

A systematic review on non-cystic fibrosis bronchiectasis has reported that oscillatory PEP devices are the preferred mode of therapy compared with other techniques, such as active-cycle-of-breathing technique with or without gravity-assisted drainage. ${ }^{13}$ Both devices in this study augmented secretion clearance. However, if subject preference is included, then Flutter is much preferred on the basis of speed of expectoration of clearance and several features that make the Flutter device easier to use. Due to this reason, we suggest that if a patient cannot tolerate other devices or techniques that assist with faster clearance, the Lung Flute can be offered as an alternative device. Each patient should have the opportunity to experience each therapy and choose their preferred modality. Patient preference for the device reflects a balance of comfort, convenience, ease of use, and efficacy.

There were limitations to this study. We acknowledge that this is a short-term trial, and it forms the basis of planned long-term studies. Future long-term trials are planned with other important end points evaluating exacerbation rates, exercise tolerance, and quality of life.

Because a systematic review has reported that airway clearance techniques, such as oscillatory PEP, active-cycleof-breathing technique, and gravity-assisted drainage, enhanced sputum expectoration compared with no treatment in subjects with bronchiectasis, we believed that it would be unethical to have a no-treatment control group in this study. ${ }^{6}$ Flutter has been shown to augment sputum expectoration in addition to huff and coughing alone. ${ }^{10}$ It was on this basis that each subject in this study acted as their own control when using the devices.

Eight subjects in the current study had used or were presently using the Flutter. No subject had previously used the Lung Flute because it was a new device in the market. There may have been some degree of bias toward the Flutter by subjects who had previously used it. However, 2 subjects in 
this study who had previously used the Flutter preferred the Lung Flute because they found the oscillatory wave when expiring through the Flutter uncomfortable.

Using sputum weight as an outcome measure has its limitations due to day-to-day variability, within-day variability, and swallowing of secretions. ${ }^{24}$ The subjects in this study were accustomed to expectorating sputum, and the treatment session was supervised by a physiotherapist who discouraged subjects from swallowing sputum. The contamination of saliva can be eliminated using dry sputum weight. However, mucus density can be different among subjects and people with thick mucus, and a reduced volume of sputum may present with the same dry weight as those with thin mucus and a higher volume of sputum. In addition, there is no valid or reliable test to assess dry sputum weight. However, the crossover design and daily sessions conducted at the same time of day helped to ensure greater within-subject accuracy for dry and wet sputum weight results.

A review of the limited evidence of the efficacy of sputum clearance techniques in subjects with COPD showed airway clearance techniques to be useful only in subjects who produce $>25 \mathrm{~mL}$ (1 tablespoon) of sputum/d..$^{25}$ For this reason, we included subjects with bronchiectasis who produced $\geq 25 \mathrm{~mL}$ of sputum/d, because it is unclear whether airway clearance assists subjects with bronchiectasis who have scant secretions.

\section{Conclusions}

In this single-center randomized crossover study of stable subjects with bronchiectasis, both the Flutter and the Lung Flute augmented airway clearance effectively. Most subjects expressed a preference for the Flutter because it was easier to use and seemed to clear secretions faster.

\section{ACKNOWLEDGMENTS}

We thank Niche Medical for supplying Lung Flutes for the study and Honorary Professor Jenny Peat for assistance with statistical analysis.

\section{REFERENCES}

1. McShane PJ, Naureckas ET, Tino G, Strek ME. Non-cystic fibrosis bronchiectasis. Am J Respir Crit Care Med 2013;188(6):647-656.

2. Main E, Grillo L, Rand S. Airway clearance strategies in cystic fibrosis and non cystic fibrosis bronchiectasis. Semin Respir Crit Care Med 2015;36(2):251-266.

3. Prior JA, Webber BA, Hodson ME, Batten JC. Evaluation of the forced expiration technique as an adjunct to postural drainage in the treatment of cystic fibrosis. Br Med J 1979;2(6187):417-418.

4. Hough A. Physiotherapy in respiratory and cardiac care: an evidence-based approach, 4th edition. South Melbourne, Australia: Cengage Learning; 2014:234-237, 346-347.

5. Martínez-García MA, Soler-Cataluña J, Perpiñá-Tordera M, RománSánchez P, Soriano J. Factors associated with lung function decline in adult pateints with stable non-cystic fibrosis bronchiectasis. Chest 2007;132(5):1565-1572.
6. Lee AL, Burge AT, Holland AE. Airway clearance techniques in bronchiectasis. Cochrane Database Syst Rev 2015;(11):CD0008351.

7. Darbee JC, Ohtake PJ, Grant BJ, Cerny FJ. Physiologic evidence for the efficacy of positive expiratory pressure as an airway clearance technique in patients with cystic fibrosis. Phys Ther 2004;84(6):524-537.

8. App EM, Kieselmann R, Reinhardt D, Lindemann H, Dasgupta B, King M, Brand P. Sputum rheology changes in cystic fibrosis lung diesease following two different types of physiotherapy; flutter vs autogenic drainage. Chest 1998;114(1):171-177.

9. Tambascio J, de Souza LT, Lisboa RM, Passarelli Rde C, de Souza HC, Gastaldi AC. The influence of Flutter VRP1 components on mucus transport of patients with bronchiectasis. Respir Med 2011; 105(9):1316-1321.

10. Figueiredo PH, Zin WA, Guimarães FS. Flutter valve improves respiratory mechanics and sputum production in patients with bronchiectasis. Physiother Res Int 2012;17(1):12-20.

11. Thompson CS, Harrison S, Ashley J, Day K, Smith DL. Randomised crossover study of Flutter device and the active cycle breathing in non-cystic fibrosis bronchiectasis. Thorax 2002;57(5):446-448.

12. Eaton T, Young P, Zeng I, Kolbe J. A randomized evaluation of the acute efficacy, acceptability and tolerability of flutter and active cycle breathing with and without postural drainage in non-cystic fibrosis bronchiectasis. Chron Respir Dis 2007;4(1):23-30.

13. Lee AL, Williamson HC, Lorensini S, Spencer LM. The effects of oscillating positive expiratory pressure therapy in adults with stable non-cystic fibrosis bronchiectasis: a systematic review. Chron Respir Dis 2015;12(1):36-46.

14. Volsko TA, DiFiore J, Chatburn RL. Performance comparison of two oscillating positive expiratory pressure devices: acapella versus flutter. Respir Care 2003;48(2):124-130.

15. Sethi S, Yin J, Anderson PK. Lung flute improves symptoms and health status in COPD with chronic bronchitis: a 26 week randomized controlled trial. Clin Transl Med 2014;3:29.

16. Babalo RDC, Balanag V, Ong-Cabrera G. Comparison of the flutter device (lung flute) to active cycle breathing technique (ACBT) in hospitalised patients with bronchiectasis: a pilot study. Phil J Chest Dis 2012;15(1):41-48.

17. Cecins NM, Jenkins SC, Pengelley J, and Ryan G. The active cycle of breathing techniques to tip or not to tip? Respir Med 1999;93(9):660-665.

18. Rubin BK, Ramirez O, Zayas JG, Finegan B, and King M. Collection and analysis of respiratory mucus from subjects without lung disease. Am Rev Respir Dis 1990;141(4):1040-1043.

19. Tamaoki J, Takeyama K, Tagaya E, and Konno K. Effect of clarithromycin on sputum production and its rheological properties in chronic respiratory tract infections. Antimicrob Agents Chemother 1995;39(8): 1688-1690.

20. Zhang M, Tang J, Mujumdar A, and Wang S. Trends in microwave related drying of fruits and vegetables. Trends Food Sci Technol 2006;17(10):524-534.

21. McCarren B, and Alison JA. Physiological effects of vibration in subjects with cystic fibrosis. Eur Respir J 2006;27(6):1204-1209.

22. King M, Phillips DM, Gross D, Vartian V, Chang HK, Zidulka A. Enhanced tracheal mucus clearance with high frequency chest wall compression. Am Rev Respir Dis 1983;128(3):511-515.

23. Fujita A, Murata K, and Takamori M. Novel method for sputum induction fusing the lung Flute in patients with suspected pulmonary tuberculosis. Respirology 2009;14(6):899-902.

24. Rossman CM, Waldes R, Sampson D, and Newhouse MT. Effect of chest physiotherapy on the removal of mucust in patients with cystic fibrosis. Am Rev Respir Dis 1982;126(1):131-135.

25. Tang CY, Taylor NF, and Blackstock FC. Chest physiotherapy for patients admitted to hospital with an acute exacerbation of chronic obstructive disease: a systematic review. Physiotherapy 2010;96(1):1-13. 